\title{
edificio mixto
}

P. BUSSAT Y J. M. LAMUNIERE, arquitectos

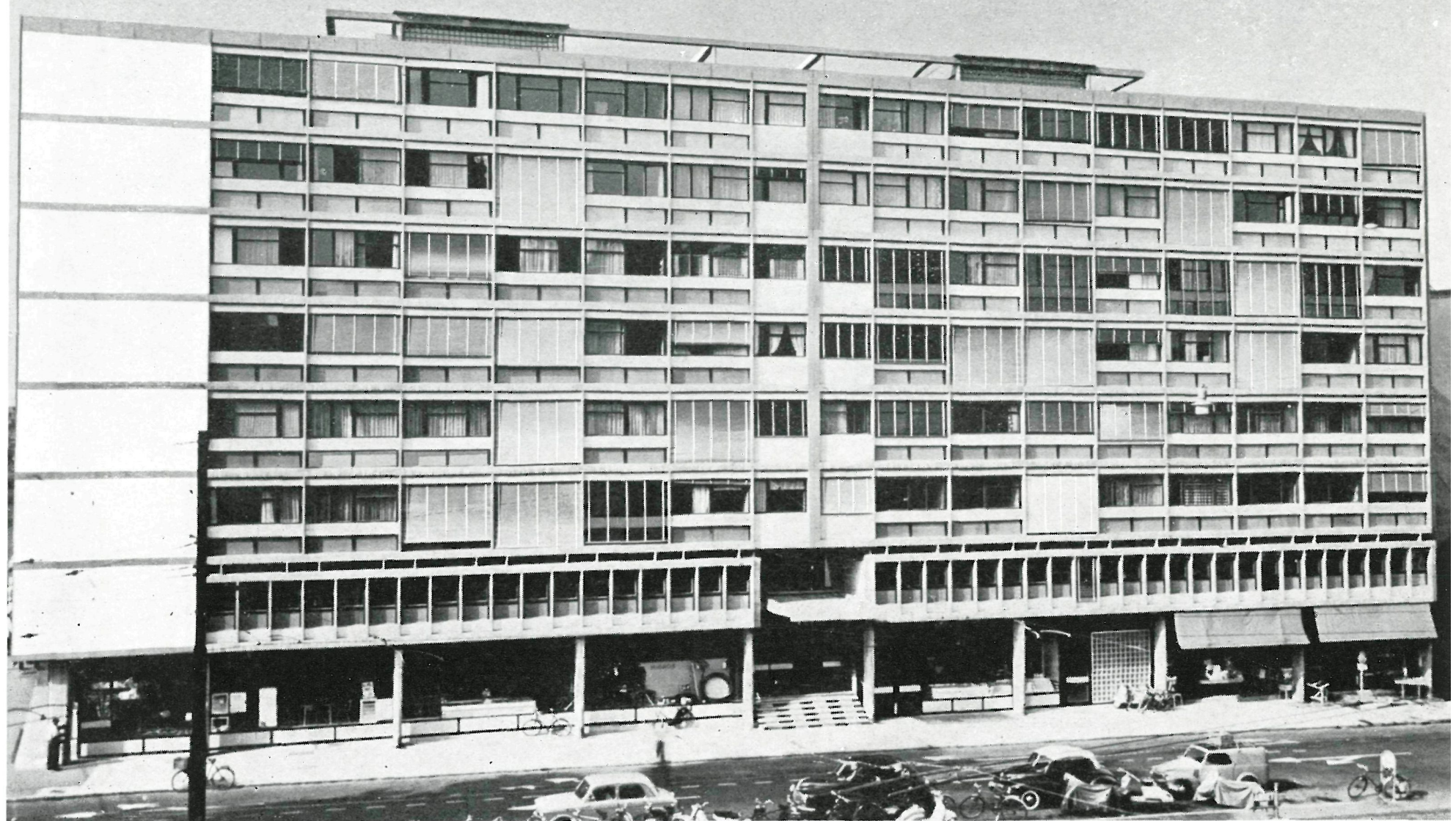

$125 \cdot 25$

Se trata de un edificio doble, cuyos pisos superiores están reservados para viviendas particulares, el entresuelo para locales administrativos y la planta baja para almacenes y otros locales comerciales.

Esta mezcla de concepto esta justificada por la situación extrema, en el primer cinturón de boulevards, que forma el límite del centro urbano. Es un ejemplo típico de nuestra época, un edificio destinado a ser sometido a cambios rápidos, a causa de la amplificación de la ciudad; su concepto tiene que ser capaz de adaptarse a la demanda actual, por ejemplo, debe permitir la conversión de las viviendas en oficinas.

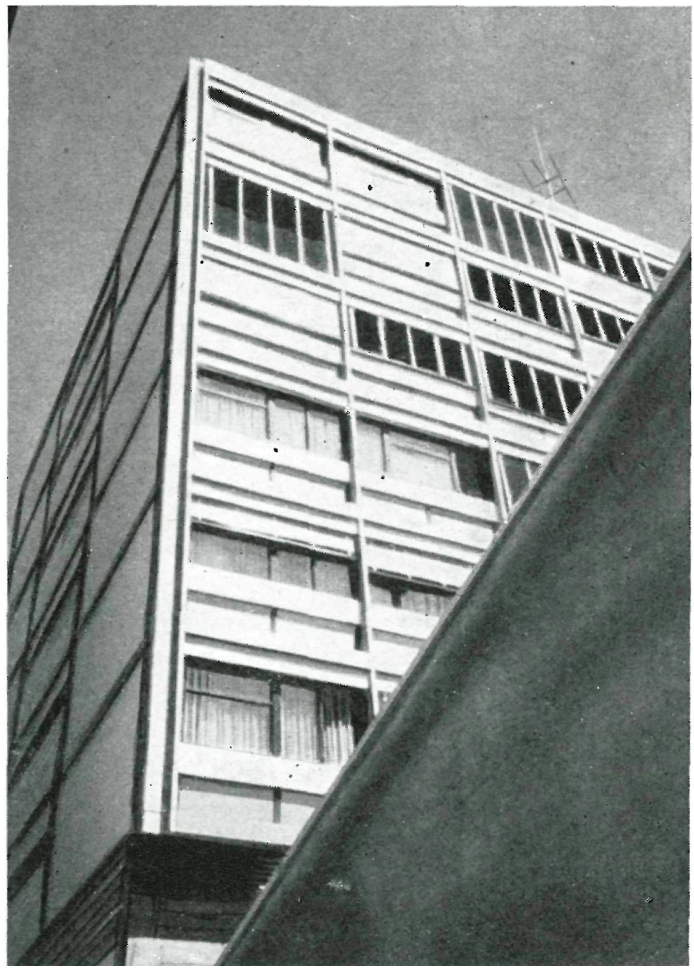




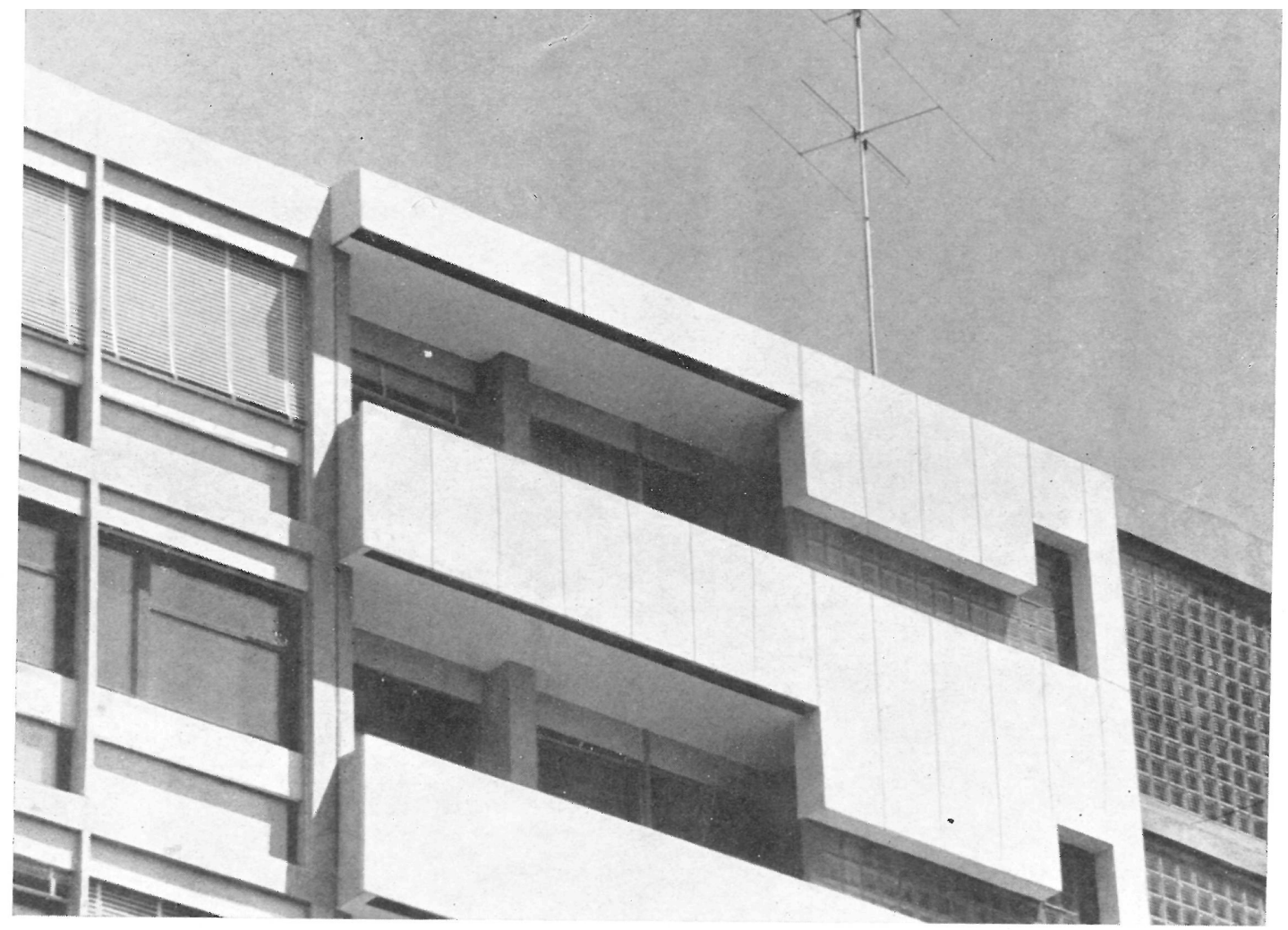

El sistema del esqueleto consiste en una estructura de forjados y de soportes, sin muros de carga. La organización interior puede cambiar independientemente sin afectar la estabilidad de la construcción. Las fachadas exteriores están realizadas por elementos de cristal diferente, independiente igualmente de la estructura; contienen un elemento de calefacción, un convector, y una protección contra el sol y la luz mediante una cortina de láminas al exterior.

La cubierta constituye una terraza con acceso para los habitantes.

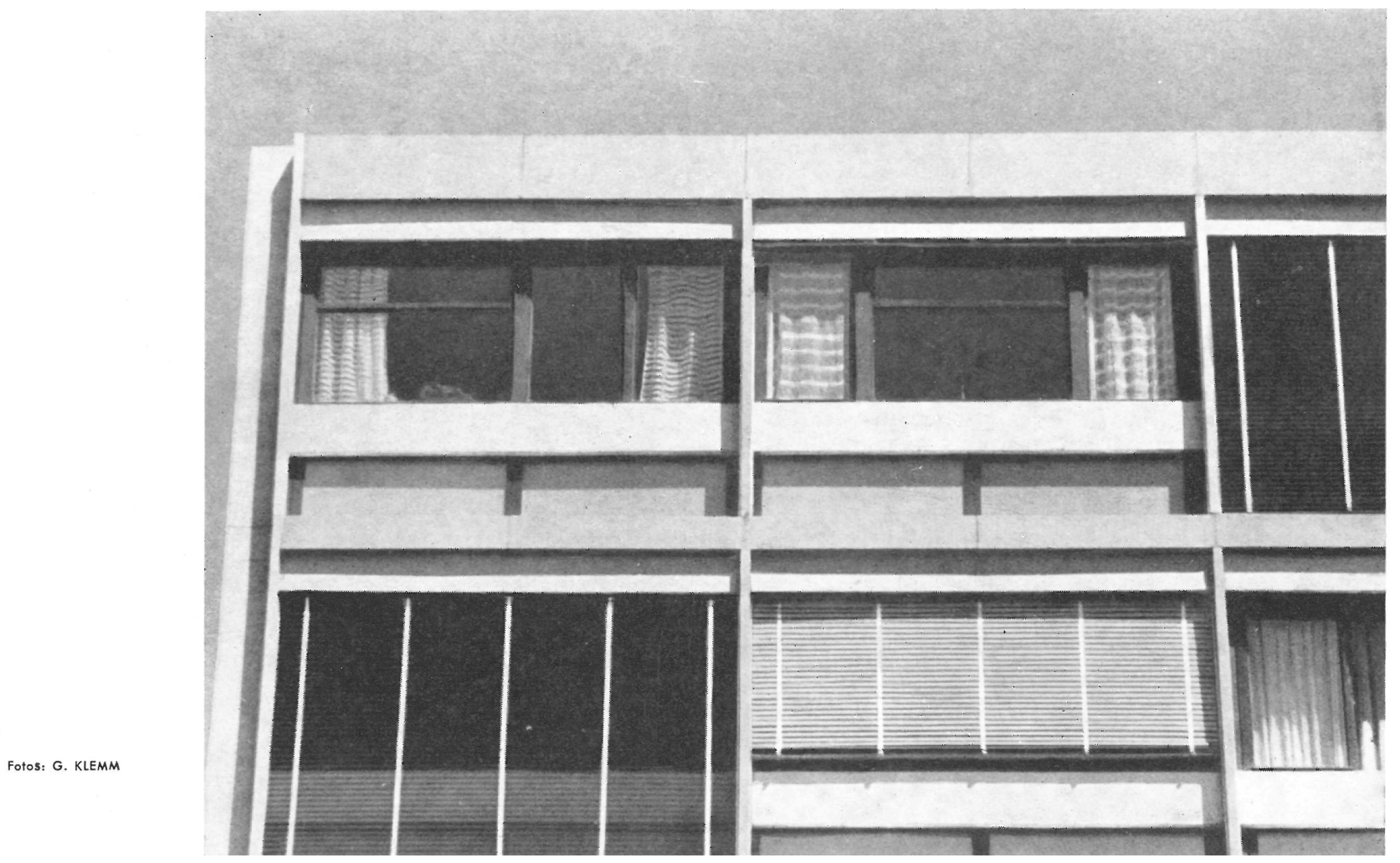




\section{situación}

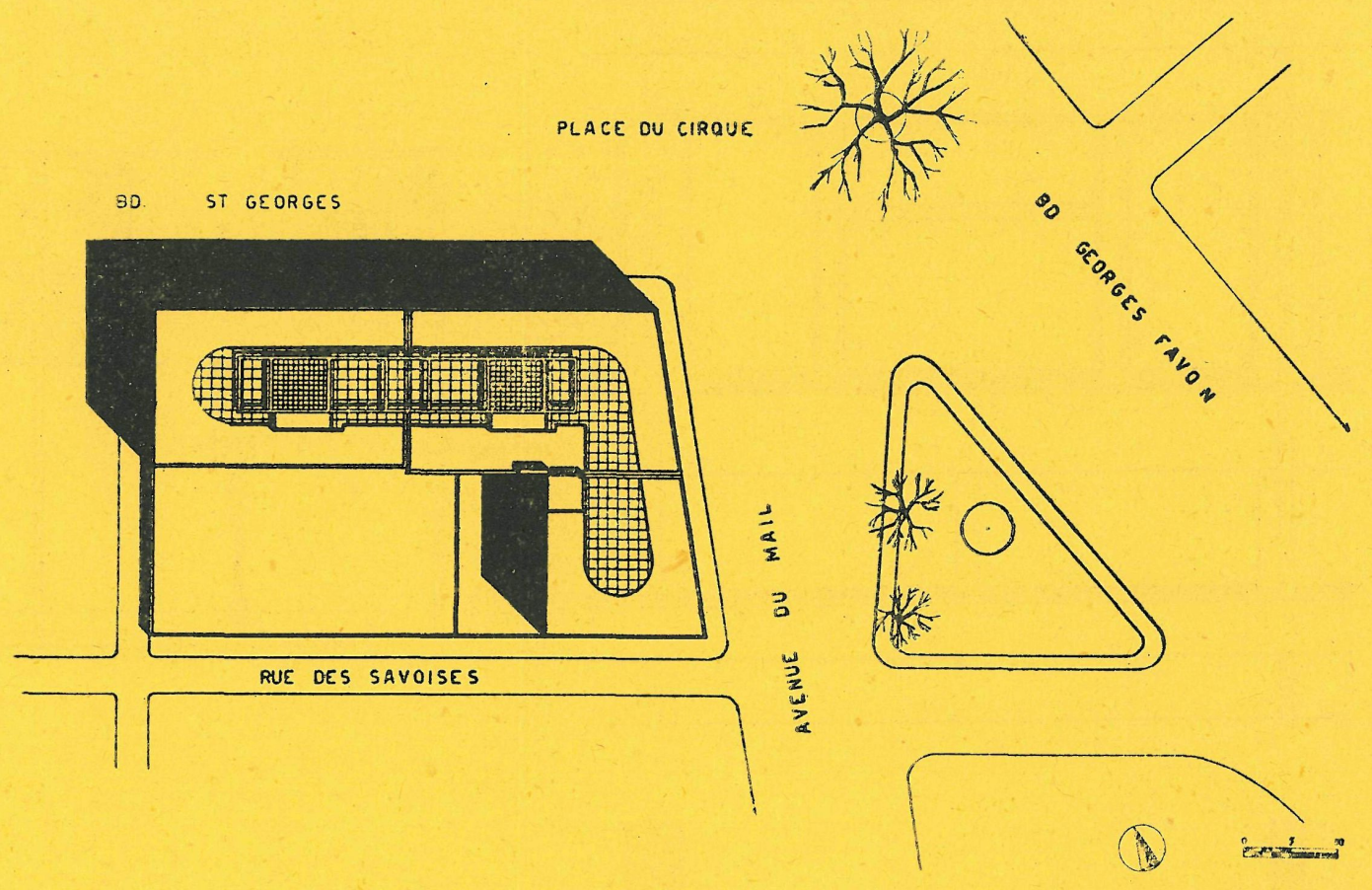

\section{planta tipo}

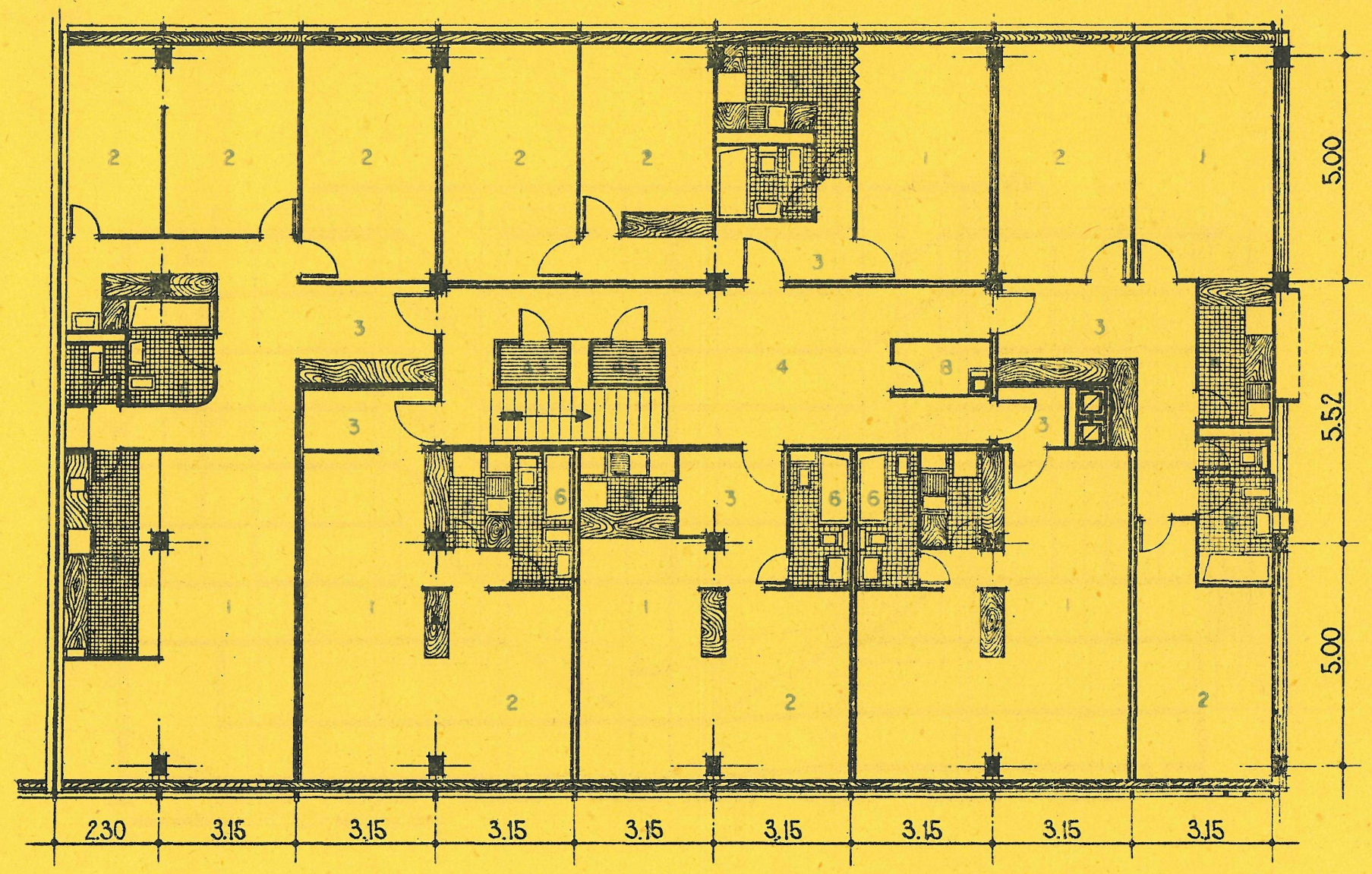

1. Estar.-2. Dormitorio. -3. Vestibulo-4. Hall
5. Cocina - - B. Baño-7. W. C.-8. Trastero. 

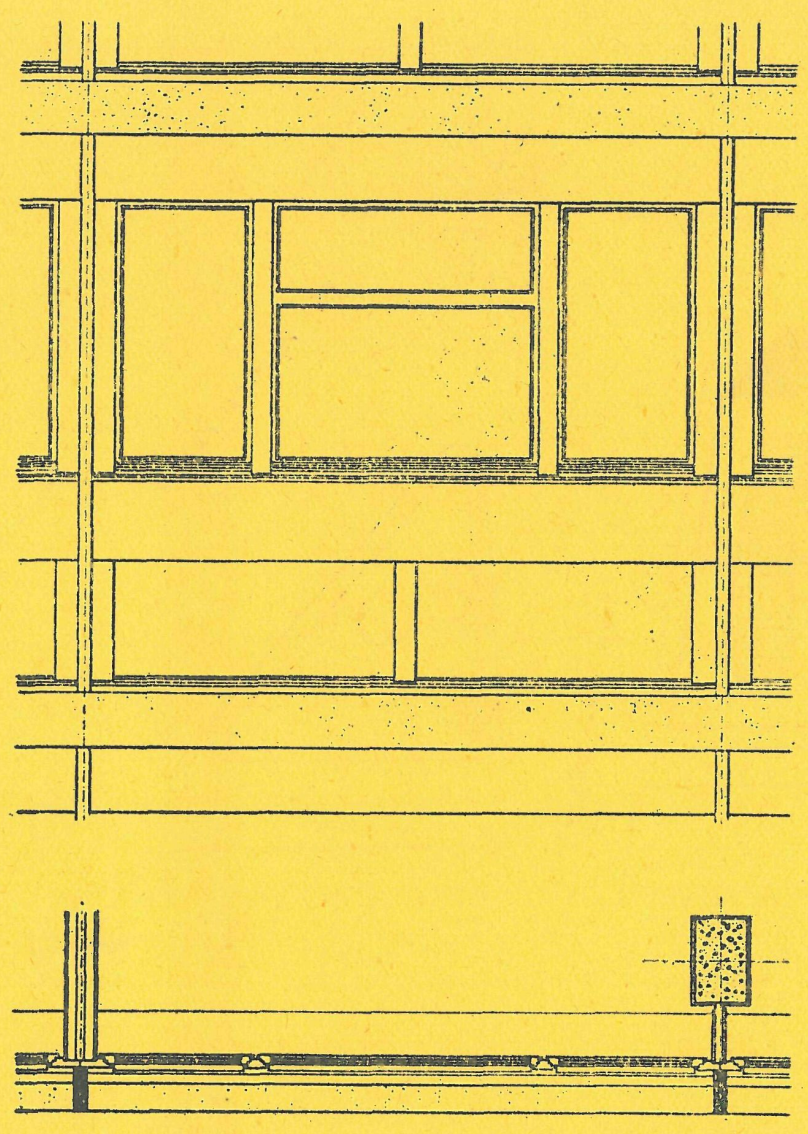

\section{detalle de fachada}

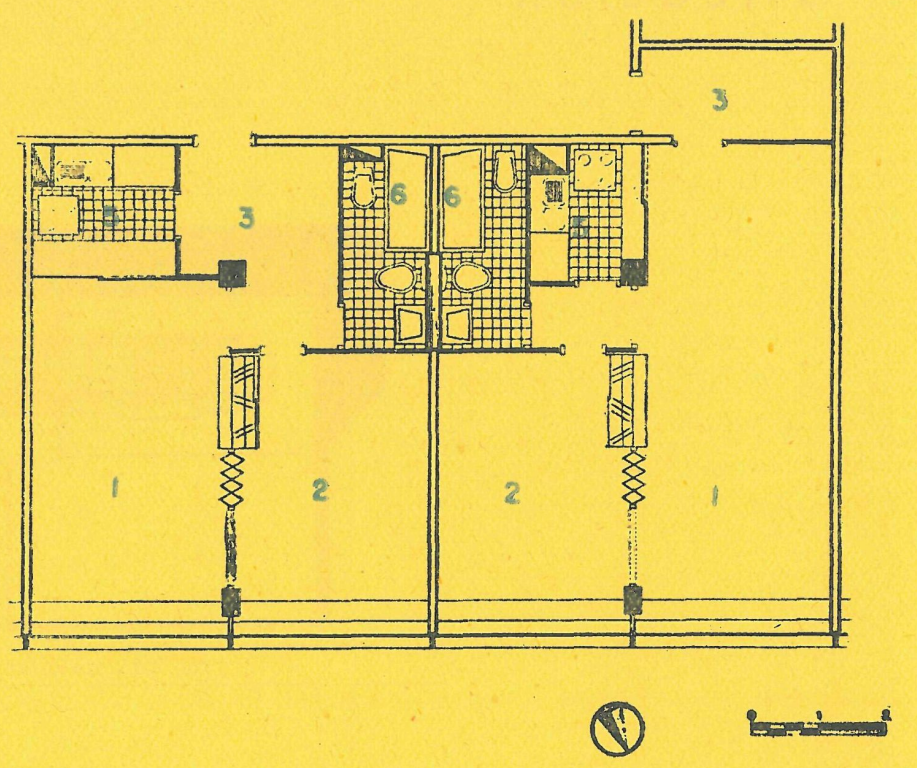

\section{planta tipo}

Estar. 1

Dormitorio. 2

Vestibulo. 3

Cocina. 5
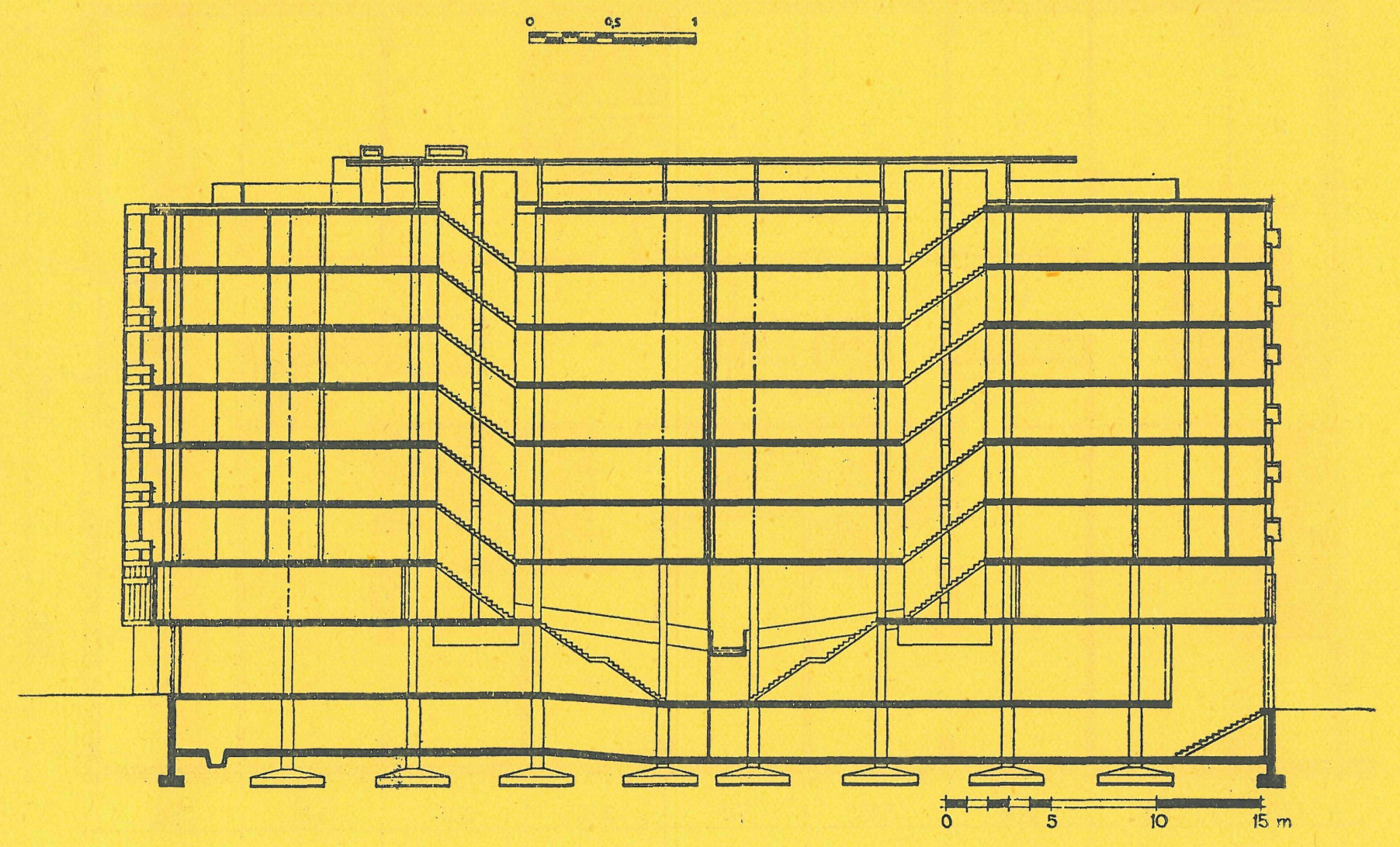

sección longitudinal 